\title{
O sistema penitenciário brasileiro e a ineficiência da ressocialização dos condenados
}

\author{
The Brazilian penitentiary system and the inefficiency of the rehabilitation of convicts \\ El sistema penitenciario brasileño y la ineficacia de la rehabilitación de los condenados
}

Michael Douglas Sousa Leite

ORCID: https://orcid.org/0000-0002-9356-1872

Faculdade Católica Santa Teresinha, Brasil

E-mail: michaeldouglas_adm@hotmail.com

Glauber Iure Cardoso de Menezes Silva

ORCID: https://orcid.org/0000-0002-8483-4488

Faculdades Integradas do Ceará, Brasil

E-mail: glauber.adv@bol.com.br

Helmo Robério Ferreira de Meneses

ORCID: https://orcid.org/0000-0001-9326-8548

Faculdades Integradas do Ceará, Brasil

E-mail: helmo_rob@hotmail.com

Cristóvão Maia Filho

ORCID: https://orcid.org/0000-0003-3605-5743 Universidade Regional do Cariri, Brasil

E-mail: cristovaomaia@zipmail.com.br

Ricardo Paiva Varandas

ORCID: https://orcid.org/0000-0003-3892-2740

Centro Universitário Uniesp, Brasil

E-mail: ricardovarandas@yahoo.com.br

Domingos Gualberto de Oliveira

ORCID: https://orcid.org/0000-0002-8708-2568

Universidade Federal de Campina Grande, Brasil

E-mail: domingos.oliveira@uscsonline.com.br

Jefferson Thiago da Silva Victor

ORCID: https://orcid.org/0000-0002-8867-9032

Faculdades Integradas do Ceará, Brasil

E-mail: jeffersonethiane10@gmail.com

Rayanna Cândido Gomes

ORCID: https://orcid.org/0000-0002-4936-5866

Faculdades Integradas do Ceará, Brasil

E-mail: rayannacandido.advocacia@gmail.com

E-mail: helmo_rob@hotmail.com

Ednelton Helejone Bento Pereira

ORCID: https://orcid.org/0000-0001-5827-0511

Faculdades Integradas do Ceará, Brasil

E-mail: jonebpereira@hotmail.com

Vinícius Campos de França

ORCID: https://orcid.org/0000-0002-2512-8241

Universidade Federal de Campina Grande, Brasil

E-mail: viniciuscamposf@gmail.com

Sauly Martinho Gomes de Sousa

ORCID: https://orcid.org/0000-0001-6181-0363

Faculdades Integradas do Ceará, Brasil

E-mail: administracao@sousa.pb.gov.br

Kaio Luís de Azevêdo Santos

ORCID: https://orcid.org/0000-0002-5904-8549

Faculdade Católica Santa Teresinha, Brasil

E-mail: kaioluis@hotmail.com

Weslley Alves de Araújo

ORCID: https://orcid.org/0000-0001-6019-6867

Faculdades Integradas do Ceará, Brasil

E-mail: weslley.igt@hotmail.com

Márcia Rubia Batista Teixeira

ORCID: https://orcid.org/0000-0002-0248-3195

Faculdades Integradas do Ceará, Brasil

E-mail: marciaescritorioadv@icloud.com

Agilio Tomaz Marques

ORCID: https://orcid.org/0000-0001-8364-5063

Universidade Federal de Campina Grande, Brasil

E-mail: agiliotomaz@hotmail.com 


\author{
Rodrigo Rodrigues da Silva \\ ORCID: https://orcid.org/0000-0001-5248-0964 \\ Faculdades Integradas do Ceará, Brasil \\ E-mail: rodrigorsilva97@gmail.com \\ Mariana Ferreira Pessoa \\ ORCID: https://orcid.org/0000-0002-1563-5469 \\ Universidade do Estado do Rio Grande do Norte, Brasil \\ E-mail: marianafepessoa@gmail.com \\ Laerte Ferreira de Morais França \\ ORCID: https://orcid.org/0000-0002-4147-1920 \\ Universidade Federal de Campina Grande, Brasil \\ E-mail: laertefmf@yahoo.com.br \\ Lincon Bezerra de Abrantes \\ ORCID: https://orcid.org/0000-0002-8362-5334 \\ Universidade Federal de Campina Grande, Brasil \\ E-mail: linconabrantes@hotmail.com \\ Jéssica Ruana Lima Mendes \\ ORCID: https://orcid.org/0000-0002-6513-0987 \\ Universidade Federal de Campina Grande, Brasil \\ E-mail: ruana_mendes@hotmail.com
}

\begin{abstract}
Resumo
O artigo objetiva analisar a aplicação dos meios legais que conduzem o cumprimento da pena no sistema penitenciário, demonstrando a falta de eficácia do sistema penitenciário brasileiro em questão da ressocialização. Como aspectos metodológicos adotou-se uma pesquisa bibliografia, onde teve como base: artigos, monografias, dissertações e teses sobre o assunto tendo em vista a necessidade de se identificar os estudos já realizados. Os resultados mostraram que a situação atual em que o sistema carcerário, em total desacordo com os princípios da Constituição Federal de 1988 e da Lei de Execução Penal, onde é necessário se buscar formas que permitam a real aplicação, e não apenas na letra morta da lei, dos princípios, trazendo, benesses aproveitadas por toda a sociedade. Para que haja mudança do setor, é necessário que se tenha uma movimentação política, o que não é muito animador, posto que os presos se distanciam das prioridades dos políticos, muito em decorrência do desinteresse da própria sociedade, que pouco se importam com as condições do cumprimento de pena de quem comete um crime. Contudo, não é pelo fato do fracasso do sistema que se deve pensar em abolição da pena. É necessário medidas a fim de tentar diminuir as mazelas e a estigmatização dos presos, como a privatização, a justiça restaurativa e a ressocialização por meio da educação.
\end{abstract}

Palavras-chave: Humanização; Sistema penitenciário; Penas; Ressocialização.

\begin{abstract}
The article aims to analyze the application of the legal means that lead to the execution of the sentence in the penitentiary system, demonstrating the lack of effectiveness of the Brazilian penitentiary system in terms of resocialization. As methodological aspects, a bibliographic research was adopted, which was based on: articles, monographs, dissertations and theses on the subject, bearing in mind the need to identify the studies already carried out. The results showed that the current situation in which the prison system, in total disagreement with the principles of the Federal Constitution of 1988 and the Criminal Execution Law, where it is necessary to look for ways that allow the real application, and not just in the dead letter of the law, of principles, bringing benefits enjoyed by the whole society. In order for the sector to change, it is necessary to have political movement, which is not very encouraging, as prisoners distance themselves from the priorities of politicians, largely as a result of society's disinterest, who care little about conditions of serving the sentence of a person who commits a crime. However, it is not because of the failure of the system that the abolition of the penalty should be considered. Measures are needed in order to try to reduce the ailments and stigmatization of prisoners, such as privatization, restorative justice and re-socialization through education.
\end{abstract}

Keywords: Humanization; Penitentiary system; Feathers; Resocialization.

\title{
Resumen
}

El artículo tiene como objetivo analizar la aplicación de los medios legales que conducen a la ejecución de la pena en el sistema penitenciario, demostrando la falta de efectividad del sistema penitenciario brasileño en términos de resocialización. Como aspectos metodológicos se adoptó una investigación bibliográfica, que se basó en: artículos, monografías, disertaciones y tesis sobre el tema, teniendo en cuenta la necesidad de identificar los estudios ya realizados. Los resultados evidenciaron que la situación actual en la que se encuentra el sistema penitenciario, en total desacuerdo con los principios de la Constitución Federal de 1988 y la Ley de Ejecución Penal, donde es necesario buscar vías que permitan la aplicación real, y no solo en el letra muerta de la ley, de los principios, que traen beneficios de que disfruta toda la sociedad. Para que el sector cambie es necesario un movimiento político, lo cual no es muy alentador, ya que los presos se distancian de las prioridades de los políticos, en gran parte por el desinterés de la sociedad, a la que poco le importan las condiciones de cumplimiento de la pena de prisión. una persona que comete un delito. Sin embargo, no es debido al fracaso del sistema que deba considerarse la abolición de la pena. Se necesitan medidas para tratar de 
reducir los problemas y la estigmatización de los presos, como la privatización, la justicia restaurativa y la resocialización a través de la educación.

Palabras clave: Humanización; Sistema penitenciario; Plumas; Resocialización.

\section{Introdução}

O direito penitenciário é um conjunto de normas jurídicas, que se refere à disciplina e ao tratamento dos sentenciados. Durante muito tempo, ouvimos a respeito do falho sistema carcerário de nosso país, onde as penitenciárias superlotadas, dominadas pelo ócio e violência passam longe dos preceitos legais estabelecidos na Lei no 7.210 de 11 de julho de 1984 que é uma das mais completas existentes no mundo para o cumprimento das penas, porém não é executada de maneira adequada, já que esta Lei é clara ao dizer que a execução penal deve objetivar a integração social do condenado ou recluso, sendo adotada a teoria mista ou eclética, segundo a qual a natureza retributiva da pena não busca apenas a prevenção, mas também a humanização (Brasil, 1984; Marcão, 2021)

Nesse aspecto nota-se que há ineficácia de cumprir suas finalidades, a qual tem em primazia a ressocialização, todavia se observa que muita poucas são medidas que vêm sendo tomadas, para que de fato haja alguma mudança significativa no sistema brasileiro penitenciário, ou para que os presos/apenados e egressos tenham de fato uma mínima perspectiva real de vida fora do cárcere (Dick, 2021).

Segundo o dicionário Aurélio entende se por cárcere, Prisão ou cadeia; local onde os prisioneiros cumprem suas penas. Cela; tudo o que se pode utilizar para prender ou para aprisionar. Figurado. Dificuldade; se diz daquilo que é a razão de um problema. Cárcere privado. O local em que alguém foi mantido preso por ação de particulares (Etm. do latim: carcer.eris) (Ferreira, 2020, p. 809).

As críticas aplicadas a este sistema penitenciário não se resumem apenas a maneira em que se encontram os presos e a falta de organização e programas necessários para uma ressocialização, mas também pela aplicabilidade das penas, que vão de choque com os princípios basilares do direito penal, como com os princípios versados na nossa Constituição Federal de 1988, não atingindo de fato, a finalidade desejada (Brasil, 1988).

A finalidade da pena restritiva da liberdade é, além de extrair o condenado da sociedade, oferecer as condições necessárias para a sua ressocialização. Assim, pode-se falar que a ideia da ineficácia das penas, resta justamente do fato da punição estar conexa à ideia de ressocialização (Corrêa \& Nogueira, 2015).

O que se nota, então, é que, o único propósito que vem sendo cumprido é apenas a segregação social, pelo encarceramento, que decorre das condições das prisões estatais de hoje, quais sejam, cárceres lotados, dominados, pela violência muitas vezes, entre os presos, e que não oferecem nenhum tipo de atividade que qualifique os condenados para uma vida na sociedade. Além disso, pesa muito o fato de que não existe uma maneira definida para a devida individualização da pena dos presos, uma vez que que não é realizada uma análise dos delitos e da sua vida pregressa, o que traz como resultado, por exemplo, na convivência de detentos de alta periculosidade, com condenados de pequenos delitos, o que vaiem mão contrária à reintegração social apetecida e contra a Lei de Execução Penal (Rodrigues \& Cavalcanti, 2017).

É notório que o sistema penitenciário é algo essencial para a sociedade, e baseado nesta necessidade, buscam-se as medidas que possam sempre trazer realmente alguma melhora nas suas condições, para que a ressocialização, que é um dos principais objetivos do sistema carcerário, possa ser atingido, a exemplo os primordiais do cumprimento da pena e, de modo consequente, atenuar as condições degradantes em que se encontram os apenados, criando, alguma perspectiva para a vida em sociedade (Barcinski et al., 2017).

Desta forma, o presente trabalho tem como principal objetivo, fundamentar segundo as bases do direito penal e processual penal os princípios e os objetivos que levam a aplicabilidade dos dispositivos legais que regem o cumprimento da pena, colocando em contrapeso a situação atual em que se encontra o carcerário como também, demonstrar a ineficácia do 
sistema penitenciário diante da ressocialização objetivada, em total desacordo com os princípios da Lei de Execução Penal e da Constituição, para que se busquem meios que possibilitem a aplicação real, e não apenas na letra morta da lei, dos princípios, trazendo, benesses que seriam aproveitadas por toda a sociedade.

\section{Metodologia}

A princípio, foi necessária uma abordagem dos princípios e institutos que unificam o cumprimento da pena pelo condenado, demonstrando o contexto social, resultado de um pensamento econômico socialmente segregatício, que torna determinados setores da sociedade grupos de risco, o que aumenta por vezes a aplicação exacerbada da letra penal a elas. Por fim, após a análise dessas questões talvez seja possível buscar uma conclusão que seja melhor para a sociedade como um todo.

Para tanto, foi feita uma pesquisa bibliografia do tipo Narrativa, onde se teve como base: artigos, monografias, dissertações e teses sobre o assunto tendo em vista a necessidade de se identificar os estudos já realizados. Segundo Marconi \& Lakatos (2010), trata-se de uma metodologia imprescindível tanto para obter uma ideia precisa sobre o atual estado dos conhecimentos sobre determinado tema, como as suas lacunas e sobre ainda a contribuição das investigações para o desenvolvimento do conhecimento.

De acordo com Rother (2007) os artigos do tipo revisão narrativa são publicações mais amplas, apropriadas para discutir e descrever o desenvolvimento ou o "estado da arte" de um assunto determinado, sob ótica contextual ou teórico.

Para levantamento dos artigos e trabalhos foram utilizadas as seguintes bases: Google Acadêmico, além de livros, manuais, monografias, dissertações e teses. Os descritores usados foram "Ressocialização", "Condenados" e "Sistema Penitenciário". Ainda assim, para a seleção da amostra, foram válidos os seguintes critérios de inclusão: artigos publicados nos idiomas inglês e português, que retrataram a temática em estudo, nos últimos 25 anos, período de (1996 a 2021).

\section{Sistemas Penitenciários e Institutos do Direito Penal: Reflexões Acerca da Evolução Histórica da Humanização da Pena}

A respeito dos sistemas penitenciários, estes são concebidos por corpos de doutrinas que se efetivam por meio de formas políticas e sociais essenciais das prisões, sendo as formas de gerir as prisões e os estilos pelos quais se cumpre as penas, correspondendo a um complexo de princípios legais ou regulamentares.

Para Greco (2021, 489):

A primeira pena aplicada na história da civilização, foi por Deus, no paraíso onde Eva pecou ao comer do fruto proibido e dá-lo a Adão, causando a expulsão dos dois. A partir daí, o homem, ao viver em comunidade, seguiu o sistema de aplicação de penas toda vez que as regras da sociedade na qual estava inserido eram violadas, estabelecendo como exemplo, as leis dos hebreus, o Código de Hamurábi e de Manu.

Liszt (1999), diz que o ponto de partida da história da pena coincide com a convivência social da humanidade. Essa união social distinguiu o mandamento de Deus do estatuto dos homens, onde o crime é atentado contra a divindade e a pena a expulsão do detentor à sociedade, ideia também do autor Thomas Hobbes, onde este defendia que aquele que cometesse o crime de traição seria banido.

Assim, com diversidade cultural existente, as reações da sociedade são diferentes em relação ao meio em que está inserida, a expulsão perdeu o caráter sagrado para tornar-se privação da paz. Para Liszt (1999) a pena nada mais é do que uma reação social contra as ações antissociais, sendo a ciência criminal, o crime e a pena as principais fontes da ciência do Direito Penal, onde expõe fundamentos jurídicos, desde suas origens, natureza e distinção.

Já para Nunes (2005), no Direito Penal moderno, a pena previa três finalidades: a de prevenir o crime, reprimir a ação 
delituosa e, principalmente, recuperar o delinquente para que este tenha novamente um convívio com a sociedade.

Conforme Foucault (2014, p. 19) relata que "a forma geral de uma aparelhagem para tornar os indivíduos dóceis e úteis através de um trabalho preciso sobre seu corpo criou a instituição-prisão, antes que a lei a definisse como a pena por excelência".

A data do surgimento das prisões ainda não foi mensurada, mas, segundo Nunes (2005), [a prisão] não possui um significado absolutamente cronológico e sim cultural, sendo ajustada conforme o grau de cultura ou de civilização de cada povo. Já para o pensamento foucaultiano (2014, p. 195), “a prisão, peça essencial no conjunto das punições, marca certamente um momento importante na história da justiça penal, o seu acesso à "humanidade"”.

Contudo, podemos dizer que sua existência vem desde as Sociedades Antigas, onde a Idade Média foi à precursora em sua aplicação como forma de castigo para quem infringisse seus preceitos e também com a criação do inquérito, dando o devido conhecimento suficiente para estabelecer um julgamento.

Bitencourt (2021), fala a respeito da origem da pena, o quanto ela é tão antiga quanto à humanidade, o que dificulta estabelecer suas origens, mas a aparição da prisão-pena, conseguimos datá-la, tendo ocorrido em fins do século XVI, citando ainda que na Antiguidade, fins do século XVIII, onde a prisão era uma espécie de antessala de suplícios, onde se usava a tortura, frequentemente, para descobrir a verdade.

Na metade do século XVIII e início do século XIX, foi caracterizado por um período, onde já se escutava relatos da preexistência da prisão, neste surgiu à elaboração da penalidade de prisão, tornando-a meio punitivo, há de mencionar ainda que, a primeira prisão exclusivamente feminina surgiu somente no século XVII (Nunes, 2005).

Por relatos, a primeira prisão destinada ao recolhimento de delinquentes foi a House of Correction, entre 1550 e 1552 , em Londres, com influência dos mosteiros da Idade Média (Mirabete, 2020).

O modelo de prisão que vimos, hoje em dia, são recentes para Bitencourt (2021), a prisão é concebida modernamente como um mal necessário, sem esquecer que guarda em sua essência contradições insolúveis.

Beccaria (2017) procurou justar a respeito dos casos de arbitrariedades cometidas por autoridades públicas, as quais gozavam de prestígio social. Suas penas eram brandas, enquanto que os demais cidadãos tinham suas penas terríveis, mas também a certeza de uma pena, ou seja, aquele que violasse a Lei deveria pagar pelo delito, mas de forma justa, correspondente ao crime que praticou:

O interesse geral não é apenas que se cometam poucos crimes, mas ainda que os crimes mais prejudiciais à sociedade sejam os menos comuns. Os meios de que se utiliza a legislação para impedir os crimes, devem, portanto, ser mais fortes à proporção que o crime é mais contrário ao bem público e pode tornar-se mais frequente. Deve, portanto, haver proporção entre os crimes e as penas (Beccaria, 2017, p. 65-66).

Jeremy Bentham é um importante ícone na evolução da história prisional, com suas ideias, influenciou a maneira decisiva o tratamento penal nas prisões, formando o Sistema Penitenciário Clássico com o principal objetivo: a reeducação do preso (Beccaria, 2017).

Para Foucault (2014, p. 210-211) trata-se de qualquer maneira de fazer da prisão um local de constituição de um saber que deve servir de princípio regulador para o exercício da prática penitenciária. A prisão não tem só que conhecer a decisão dos juízes e aplicá-las em função dos regulamentos estabelecidos: ela tem que coletar permanentemente do detento um saber que permitirá transformar a medida penal em uma operação penitenciaria; que fará da pena tornada necessária pela infração uma modificação do detento, útil para a sociedade.

\subsection{Funções da Pena}

As funções da pena evoluíram de acordo com o desenvolvimento progressivo das ideias, no sentido de que o progresso 
do Estado está atrelado à pena, sendo essa uma ferramenta para facilitar e regulamentar o convívio dos homens e proteger os bens jurídicos de eventuais lesões. E com o surgimento da pena veio à tona as seguintes teorias: a Teoria absoluta ou retributiva; a Teoria relativa ou preventiva e a Teoria mista ou unificadora, que serão tratadas neste tópico (Mirabete, 2020).

Em um primeiro aspecto, temos a teoria absoluta, sendo concebida no Estado Absolutista, período histórico em que a Igreja estava atrelada intimamente ao poder. Desse modo, tal teoria trazia que a pena era um castigo, com que se expiava o pecado que foi cometido, e com a ascensão da burguesia, se tornou um meio para buscar restaurar a ordem jurídica interrompida, dessa maneira, buscando, proteger o avanço capitalista.

Com a desvinculação do Estado da religião e surgimento do Estado burguês, a punição passou a ser baseada na teoria do contrato social. Dessa forma, o caráter retributivo, pela perturbação à ordem jurídica, substitui o absoluto antes vinculado à razão divina (Yarochewsky, 2005, p. 174).

Kant estava entre os defensores desta corrente, que defendia que quem descumprisse as regras não era apto para ter direito à cidadania, ficando a encargo do soberano castigar impiedosamente aquele que transgredisse a lei. Já Hegel, justificava seu posicionamento sob o argumento da necessidade de prevalecer a vigência da vontade geral, que fora ignorada pelo delinquente ao negar a ordem jurídica (Bittencourt, 2021).

Ferrajoli (2013, p. 204) conceituou a teoria em comento:

São teorias absolutas todas aquelas doutrinas que concebem a pena como um fim em si própria, ou seja, como 'reparação', 'castigo', 'reação', ou, 'retribuição' de um crime, justificada por seu intrínseco valor axiológico, vale dizer, não um meio, e nem tampouco um custo, contudo, sim, um dever ser a meta jurídico que possui em si seu próprio fundamento. São, ao contrário das 'relativas' todas as doutrinas utilitaristas, que consideram e justificam a pena como meio para realização do fim utilitário da prevenção de futuros delitos.

Não havia desta forma, preocupação em relação a utilidade ou finalidade da pena, a única finalidade era a punição em si, com o alvo de realizar justiça.

Em seguida, como advento do Iluminismo e a transição do Estado Absoluto ao Liberal, nasceu a teoria relativa, que não procurava punir as violações ao ordenamento jurídico, e sim preveni-las. Não havia de fato uma ideia de vingança, de realizar justiça, e sim a ideia de inibir as futuras práticas delitivas, uma concepção preventiva que se subdividia em geral e especial (Rusche \& Kirchheimer, 2004).

A primeira concepção preventiva (geral), defendida entre outros por Beccaria \& Bentham, que consiste em uma espécie de coação psicológica, onde a lei intimidaria o ser humano a ponderar as suas ações para que este não delinquisse, sob a pena de ser incurso em alguma sanção. Porém, essa definição não levava em consideração a confiança do delinquente de não ser descoberto ao praticar um crime, o que não era suficiente para evitar que ele cometesse a infração (Bittencourt, 2021, p. 135).

Quanto a especial, este se dirige ao infrator exclusivamente, buscando sua intimidação, correção e inocuização. Contudo, nos casos onde não existe probabilidade de reincidência, essa teoria traria a sensação de impunidade. O ideal ressocializador, além disso, não se mostrou claro, porquanto é muito difícil de conceituar e colocar em prática (Bittencourt, 2021).

Cervini (2002, p. 46), professor uruguaio, coloca quanto à evolução da sanção até a prevenção geral:

A prisão, enquanto sanção penal de imposição generalizada não é uma instituição antiga e que as razões históricas para manter uma pessoa reclusa foram, a princípio, o desejo de que mediante a privação de liberdade retribuísse à sociedade o mal causado por sua conduta inadequada; mais tarde, obrigá-la a frear os seus impulsos antissociais e mais recentemente o propósito teórico de reabilitá-la. 
A prevenção especial esbarra, no entanto, no tratamento penitenciário, diante das condições dos estabelecimentos, da falta de pessoal qualificado e dos meios apropriados para se buscar a ressocialização. (Bittencourt, 2021).

Por fim, nasceu a Teoria Mista, adotada pelo nosso sistema penal, que consiste na mescla da teoria absoluta e da relativa, sendo a prevenção geral e as especiais, distintas em vários aspectos, de um mesmo e complexo fenômeno que é a pena, não devendo esta ir além do merecido pelo fato praticado (Greco, 2021).

Houve distinção entre o fim e o fundamento da pena. Quanto ao fundamento, se coloca que a sanção não deve se firmar em nada a não ser ao delito praticado, havendo a ideia aqui de proporcionalidade. Existiu, uma aproximação assim, dos fins preventivos, especiais e gerais, concentrando a finalidade do direito penal na ideia de prevenção (Bittencourt, 2021).

No entanto, essa teoria não foi isenta de críticos, dentre os quais Thompson (1998), que afirmou que com a soma das teorias, os efeitos delas não são suprimidos, e sim multiplicados, pelo fato de as diversas finalidades atribuídas à pena serem divergentes entre si.

Entre as alternativas colocam em debate as teorias da Prevenção Geral Positiva fundamentadora e prevenção geral positiva limitadora. A primeira não assiste razão em ser aplicada, entre outras críticas, pelo fato de que em um Estado Democrático de Direito é inadmissível que se queira impor ao cidadão determinado padrão ético, bem como que se eliminem os limites do ius puniendi (direito de punir do Estado).

Na segunda, entende-se que a finalidade a ser atingida é a da prevenção geral, nas vias intimidarias e limitadoras, sem abandonar o cunho ressocializador. Parecida com a teoria mista, porém dá-se à ressocialização outro conteúdo. É necessário um método de integração eficaz entre o preso e a sociedade, além de existir restrições que abriguem os direitos fundamentais do encarcerado (Bittencourt, 2021).

\section{A Lei de Execução Penal $n^{0}$. 7.210 de 11 de julho de 1984 e a Reintegração Social do Detento}

Na Lei $n^{\circ} .7 .210$ de 11 de julho de 1984, podemos observar uma síntese no que tange ao trabalho como meio de reintegração social do detento:

Art. 28 - O trabalho do condenado, enquanto dever social e condição de dignidade humana, terá a finalidade educativa e produtiva.

$\S 1^{\circ}$ - Aplicam-se à organização e aos métodos de trabalho precauções relativas à segurança e higiene.

$\S 2^{\circ}$ - O trabalho do condenado não está sujeito ao regime da Consolidação das Leis do Trabalho.

Art. 29 - O trabalho do condenado será remunerado, segundo prévia tabela, não podendo ser inferior a três quartos do salário mínimo.

$\S 1^{\circ}$ - O produto da remuneração pelo trabalho deverá atender:

a) à indenização dos danos causados pelo crime, desde que determinados judicialmente e não reparados por outros meios;

b) à assistência à família;

c) a pequenas despesas pessoais;

d) ao ressarcimento ao Estado das despesas realizadas com a manutenção do condenado, em proporção a ser fixada e sem prejuízo da destinação prevista nas letras anteriores.

$\S 2^{\circ}$ - Ressalvadas outras aplicações legais, será depositada a parte restante para constituição do pecúlio, em cadernetas de poupança, que será entregue ao condenado quando posto em liberdade.

Art. 30 - As tarefas executadas como prestação de serviço à comunidade não serão remuneradas.

Art. 31 - O condenado à pena privativa de liberdade está obrigado ao trabalho na medida de suas aptidões e capacidade. Parágrafo único - Para o preso provisório, o trabalho não é obrigatório e só poderá ser executado no interior do estabelecimento.

Art.32 - Na atribuição do trabalho deverão ser levadas em conta a habilitação, a condição pessoal e as necessidades futuras do preso, bem como as oportunidades oferecidas pelo mercado.

$\S 1^{\circ}$ - Deverá ser limitado, tanto quanto possível, o artesanato sem expressão econômica, salvo nas regiões de turismo.

$\S 2^{\circ}$ - Os maiores de 60 (sessenta) anos poderão solicitar ocupação adequada à sua idade.

$\S 3^{\circ}$ - Os doentes ou deficientes físicos somente exercerão atividades apropriadas é seu estado.

Art. 33 - A jornada normal de trabalho não será inferior a 6 (seis), nem superior a 8 (oito) horas, com descanso nos 
domingos e feriados.

Parágrafo único - Poderá ser atribuído horário especial de trabalho aos presos designados para os serviços de conservação e manutenção do estabelecimento penal.

Art. 34 - O trabalho poderá ser gerenciado por fundação, ou empresa pública, com autonomia administrativa, e terá por objetivo a formação profissional do condenado.

Parágrafo único - Nessa hipótese, incumbirá à entidade gerenciadora promover e supervisionar a produção, com critérios e métodos empresariais, encarregar-se de sua comercialização, bem como suportar despesas, inclusive pagamento de remuneração adequada.

Art. 35 - Os órgãos da administração direta ou indireta da União, Estados, Territórios, Distrito Federal e dos Municípios adquirirão, com dispensa de concorrência pública, os bens ou produtos do trabalho prisional, sempre que não for possível ou recomendável realizar-se a venda a particulares.

Parágrafo único - Todas as importâncias arrecadadas com as vendas reverterão em favor da fundação ou empresa pública a que alude $\mathrm{o}$ artigo anterior ou, na sua falta, do estabelecimento penal.

Art.36 - O trabalho externo será admissível para os presos em regime fechado somente em serviço ou obras públicas realizadas por órgãos da administração direta ou indireta, ou entidades privadas, desde que tomadas as cautelas contra a fuga e em favor da disciplina.

$\S 1^{\circ}$ - O limite máximo do número de presos será de $10 \%$ (dez por cento) do total de empregados na obra.

$\S 2^{\circ}$ - Caberá ao órgão da administração, à entidade ou à empresa empreiteira a remuneração desse trabalho.

$\S 3^{\circ}$ - A prestação de trabalho a entidade privada depende do consentimento expresso do preso.

Art. 37 - A prestação de trabalho externo, a ser autorizada pela direção do estabelecimento, dependerá de aptidão, disciplina e responsabilidade, além do cumprimento mínimo de um sexto da pena.

Parágrafo único - Revogar-se-á a autorização de trabalho externo ao preso que vier a praticar fato definido como crime, for punido por falta grave, ou tiver comportamento contrário aos requisitos estabelecidos neste artigo.

O trabalho prisional não constitui, portanto, per se, uma agravação da pena, nem deve ser doloroso e mortificante, mas um mecanismo de complemento do processo de reinserção social, visando a readaptação do preso, preparando-o para uma profissão, desenvolvendo hábitos de trabalho, evitando assim a ociosidade.

De acordo com os juristas Nery e Júnior (2017, p. 164) tanto quanto possível, incumbe ao Estado adotar medidas preparatórias ao retorno do condenado ao convívio social. Os valores humanos fulminam os enfoques segregacionistas. A ordem jurídica em vigor consagra o direito do preso ser transferido para local em que possua raízes, visando a indispensável assistência pelos familiares.

As penas de prisão devem determinar nova finalidade, não adianta somente castigar o indivíduo, mas sim dar aos encarcerados, condições para que eles possam ser reintegrados à sociedade de maneira efetiva (Rodrigues \& Cavalcanti, 2017).

As ações que buscam trazer a ideia de ressocialização de apenados procuram reduzir os níveis de reincidência ajudando na consequente recuperação do detento através de medidas que auxiliem na sua educação, em sua capacitação profissional e na busca da conscientização psicológica e social (Nery \& Júnior, 2017).

A penitenciária tem enquanto objetivo a reabilitação e a ressocialização dos delinquentes; esse resultado é buscado através de maneiras de retribuir o mal causado pelo apenado através da aplicação de uma pena, prevenindo novos delitos pelo temor que a penalização causará aos potencialmente criminosos, além de trazer a regeneração do apenado que deverá ser transformado e assim reintegrado à sociedade como cidadão produtivo (Rodrigues \& Cavalcanti, 2017).

O nosso sistema almeja com a pena privativa de liberdade proteger a sociedade e cuidar para que o condenado seja preparado para a reinserção (Corrêa \& Nogueira, 2015).

O ordenamento jurídico brasileiro afasta o preso da sociedade com a intenção de ressocializar, mas o que encontramos é uma situação diferente, como afirma Mirabete (2020) a ressocialização não pode ser conseguida numa instituição como a prisão. Os centros de execução penal, as penitenciárias, tendem a converter-se num microcosmo no qual se reproduzem e se agravam as grandes contradições que existem no sistema social exterior. A pena privativa de liberdade não ressocializa, ao contrário, estigmatiza o recluso, impedindo sua plena reincorporação ao meio social. A prisão não cumpre a sua função ressocializadora. Serve como instrumento para a manutenção da estrutura social de dominação (Mirabete, 2020).

Sozinha a pena não consegue reintegrar o indivíduo apenado, se faz pertinente a junção de outros meios como a 
participação da própria família para que se consigam caminhar para resultados mais favoráveis a essa reintegração do preso à sociedade (Costa \& Pinto, 2019).

Exalta-se seu papel de fator ressocializador, afirmando-se serem notórios os benefícios que da atividade laborativa decorrem para a conservação da personalidade do delinquente e para a promoção do autodomínio físico e moral de que necessita e que lhe será imprescindível para seu futuro na vida em liberdade. Ainda assim, pode-se perceber que apesar da sua luta incessante pela igualdade social entre os reeducando e cidadãos considerados livres.

\section{Considerações Finais}

Em virtude da condição caótica dos cárceres, é possível afirmar, sem dúvidas, que o sistema penitenciário brasileiro está em crise. É perceptível que mesmo com o processo de humanização existente e também anteriormente destacado pelos pensadores como Howard, Beccaria, Bentham, a onda da humanização da pena que vem de tempos atrás, na sua prática a realidade se difere muito da teoria.

A pena se distancia de sai finalidade, pois as penitenciárias hoje, não funciona como meio ressocializador para a grande maioria dos apenados, e ao invés de resguardar a dignidade dos presos, deteriora-a ante a situação crítica e desumana, em decorrência da superlotação e da falta de assistência aos apenados.

Para que haja mudança do setor, é necessário que se tenha uma movimentação política, o que não é muito animador, posto que os presos se distanciam das prioridades dos políticos, muito em decorrência do desinteresse da própria sociedade, que pouco se importam com as condições do cumprimento de pena de quem comete um crime

Contudo, não é pelo fato do fracasso do sistema que se deve falar em abolição da pena restritiva de liberdade. Alguma medida sempre vem à tona a fim de tentar minimizar as mazelas do sistema e a estigmatização dos presos, como a privatização, a justiça restaurativa e a ressocialização por meio da educação.

A primeira, a princípio, pode se mostrar interessante pelo fato de poder trazer melhorias para o cumprimento da pena. Porém a ideia de vir uma empresa privada para investir em um setor que cuida da liberdade individual do cidadão, que deveria ser regulada pelo Estado não é muito interessante, especialmente em um país corrupto como o Brasil.

A justiça restaurativa é uma medida que tem mostrado bons resultados nos países em que foi implantada, sendo, inclusive, incorporada ao anteprojeto do novo Código Penal brasileiro. Contudo, é mais uma medida preventiva para evitar o cárcere, assim como as penas substitutivas, do que efetiva para aqueles que já cumprem pena.

Como sugestão de pesquisas futuras, destaca-se a necessidade de analisar dados estatísticos do sistema carcerário brasileiro dos últimos anos e propor políticas públicas eficazes para a ressocialização dos condenados.

\section{Referências}

Barcinski, M., Cúnico. S. D., \& Brasil, M. V. (2017). Significados da ressocialização para agentes penitenciárias em uma prisão feminina: entre o cuidado e o controle. Temas psicol., 25(3).

Beccaria, C. (2017). Dos delitos e das penas. Tradução Torrieri Guimarães. Edipro, Edição de Bolso.

Bitencourt, C. R. (2021) Tratado de Direito Penal: Parte Geral 1. (27a ed.), Saraiva.

Brasil. Constituição (1988). Constituição da República Federativa do Brasil. Senado.

Brasil. (1984). Lei $n^{\circ} 7.210$, de 11 de julho de 1984. Institui a Lei de Execução Penal. Diário Oficial da União de 13 de julho de 1984 . Brasília.

Cervini, R. (2002). Os processos de descriminalização. (2a ed.), RT.

Corrêa, M. F. C., \& Nogueira, J. P. F. (2015). O papel do trabalho na construção da consciência dos recuperados durante a reclusão. Revista DisSoL - Discurso Sociedade e Linguagem, 2(2), 45-54.

Costa, F. V., \& Pinto, A. A. (2019). A ressocialização do detento a partir do prazo para o cumprimento da função social da empresa na sociedade contemporânea. Revista Direitos Sociais e Políticas Públicas (UNIFAFIBE), 7(3), 99-132. 
Research, Society and Development, v. 11, n. 2, e7711225310, 2022

(CC BY 4.0) | ISSN 2525-3409 | DOI: http://dx.doi.org/10.33448/rsd-v11i2.25310

Dick, C. S. (2021). Ressocialização Do Preso: Uma Revisão Bibliográfica. Revista Ibero-Americana de Humanidades, Ciências e Educação, 7(1), 518-528.

Ferrajoli, L. (2013). Direito e Razão: Teoria do garantismo penal. (4a ed.), Revista dos Tribunais.

Ferreira, A. B. de H. (2020). Dicionário da língua portuguesa. (9a ed.), Positivo.

Foucault, M. (2014). Vigiar e punir nascimento da prisão. Tradução de Raquel Ramalhete. (42a ed.), Vozes.

Greco, R. (2021). Direitos Humanos, sistema prisional e alternativas à privação de liberdade. (6a ed.), Saraiva.

Listz, F. V. (1999). Tratado de derecho Tomo II. Biblioteca Jurídica de Autores Españoles y extranjeros. Editora Reus.

Marcão, R. (2021). Curso de Execução Penal. (18a ed.), Saraiva.

Marconi, M. A., \& Lakatos, E. M. (2010). Fundamentos de Metodologia Científica. Atlas Editora.

Mirabete, J. F. (2020). Manual de Direito Penal, Volume 1: parte geral, arts. $1^{\circ}$ a 120 do CP. (34a ed.), Ed. Atlas.

Nery, R. M. de A., \& Júnior, N. N. (2017). Constituição Federal Comentada e Legislação Constitucional. (6a ed.), Revista dos Tribunais.

Nunes, A. (2005). A realidade das prisões brasileiras. Nossa Livraria.

Rodrigues, V. F. S., \& Cavalcanti, S. C. M. (2017). O Sistema Prisional e a Ressocialização do preso através do trabalho. Revista FACISA on-line. Barra do Garças-MT, 6(2), 47- 62 .

Rother, E. T. (2007). Revisão sistemática X revisão narrativa. Acta paul. enferm., 20(2)

Rusche, G., \& Kirchheimer, O. (2004). Punição e estrutura social. (2a ed.), Revan.

Thompson, A. (1998). A Questão Penitenciária. (4a ed.), Forense.

Yarochewsky, L. I. (2005). Da reincidência criminal. Mandamentos. 